PESQUISA

"Ph.D. - Antropologia Social UFPa/ENSP.

\section{Interdisciplinaridade e suas práticas em documentos de "Avaliação e Perspectivas" do CNPq 1978, 1982.}

\author{
Samuel Sá*
}

INTRODUÇÃo

O tema da interdisciplinaridade tem merecido referências incidentais nos meios de comunicação de massa: um programa de televisão sobre Centros Interdisciplinares de Ciência ou uma alusão a uma Fundação Internacional e Interdisciplinar de Aids. Entretanto, ainda é escasso o aprofundamento do significado como relação entre o conceito e suas práticas. $O$ presente artigo faz parte de um estudo nessa direção.

$\mathrm{O}$ autor tem acompanhado uma década de experiências e de indagações mas, somente, agora se dispõe a sistematizá-las em uma análise. É que, em 1987, já não é verdade o que o filósofo Georges Gusdorf escreveu em 1977: falam muito sobre este assunto mas ninguém fala contra 0 mesmo (Georges Gusdorf, 1977: 581). Atualmente, o estado da questão não pode tomar o tema como representação de um modismo ou de uma panacéia inconseqüente e abstrata.

E possivel encontrar referências incidentais ou não, à interdisciplinaridade em documentos assinados por técnicos do Ministério da Educação, como do atual diretor da Capes ou de um ex-membro do Conselho Federal de Educação. Mas ela não é obje to explícito de políticas oficiais, muito mais tendentes para o status quo da fragmentação. (Edson de Souza Machado: 1980 e Armando Mendes, 1986.) O primeiro, faz réerência incidental e o seguñdo, referência explícita.

Uma das motivações para este estudo resulta de que, além do lado oficial, ideológico e sociográfico, é possível examinar os documentos do tipo "Avaliação e Perspectivas", do CNPq, como uma fonte de referências, vinda da experiência ou da expectativa, relacionada com a interdisciplinaridade. Uma releitura metódica em busca da relação unidisciplinaridade (dominante) e interdisciplinaridade 
(emergente) permite coletar dados que facilitam a análise. Essa análise toma, como pressupostos, outros textos provocados pela contribuição do filósofo brasileiro, Hilton Japiassú e da socióloga, Miriam Limoeiro.

Em outro nivel, a mo tivaçấo deriva do conhecimento das conexōes entre interdisciplinaridade e Saúde Coletiva. Basicamente, no mesmo mês de março de 1986 o Ministério da Saúde do Brasil fazia realizar a VIII Conferência Nacional de Saúde, em cujas conclusões há uma implicação da interdisciplinaridade tanto pelo conceito de saúde utilizado como pelo interesse em equipes multiprofissionais, como parte de uma organização social do conhecimento e, não, por efeito de mera contiguidade; e a OMS publicou um número especial da revista Saúde no Mundo (Março 86) reservada para o tema da cooperaçăo intersetorial, que aparece com um outro nome, para práticas de interdisciplinaridade. Esta conjuntura ilustra uma situação, onde ocorre uma demanda e um processo para "tirar de letra" a interdisciplinaridade.

Como parte de um projeto maior, o presente estudo confronta dados secundários e um referencial teórico. Toman do dados secundários disponfveis, este passo da pesquisa requer a continuida de do exame: a busca dos volumes que faltam para a coleção de 1978, bem como os demais de 1982. Há uma ênfase na área da saú de, inclusive pelas razð̋es indicadas acima. Há outra ênfase nos aspectos práticos, por uma opção heurística de que o cohecimento só avança à me dida em que relaciona teoria e práticas.

02 - Sinopse de 1978.

In ter disciplinaridade, em documen tos de "Avaliação \& Perspectivas" do CNPq, 1978: cinco das nove áreas.

A fim de reunir informações sobre o título acima, a tabela, a seguir, procura registrar os dados disponíveis:

De modo mais detalhado o que cada uma das disciplinas in cluiu como significativo se desd obra do modo seguinte:

1 - Na área de Física

"As áreas in terdisciplinares, relaciona das com este documento, compreendem campos de pesquisa que reúnem duas ou mais das principais áreas da ciência ou da tecnologia, uma delas sendo a física. Consideramos aqui, apenas, algumas das subáreas enquadradas nesta definiçãa: 1 Ciência dos ma teriais - situada entre a física e a tecnologia dos materiais. 2 - Físico-Química - problemas de química resolvidos com técnicas físicas. 3 - Dispositivos elétricos e magnéticos - fronteira entre a física de estado sólido e a tecnologia. 4 - Biofísica, Física Médica e Engenharia Biomédica - físicos no estudo dos processos biológicos (Área essencialmente interdisciplinar). 5 - Fontes de energia 


\section{PESOUISA}

Referências à prática ou d̀ expectativa de multidisciplinaridade ou in terdisciplinaridade em documentos, "A valiaçäo e perspectivas" (CNPq - 1978).

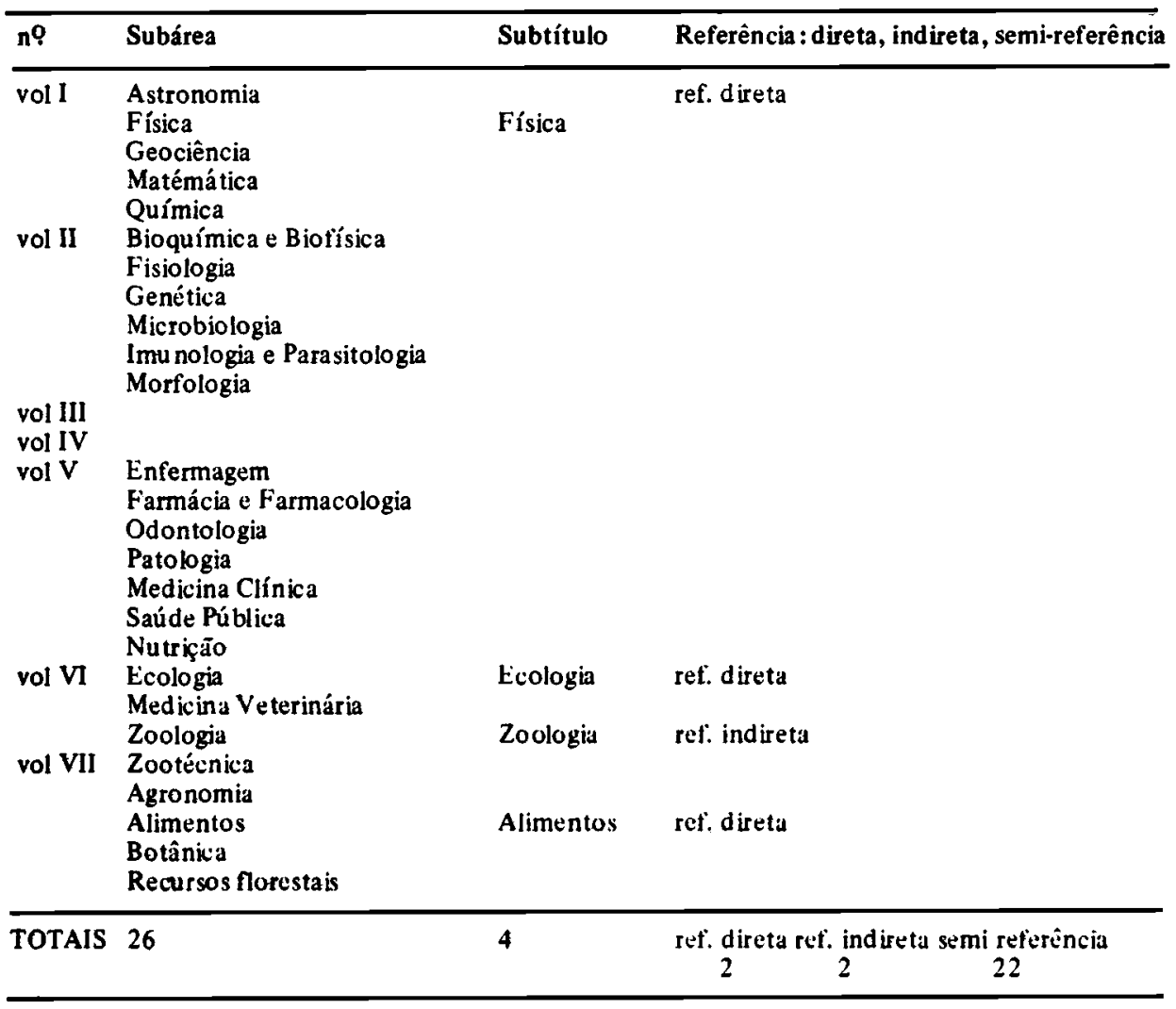

NOTA: não disponível vol. IIl, IV, VIII, IX 
não-convencionais. Muitos físicos estão participando no estudo dos problemas de energia, a lado dos engenheiros, economistas, urbanistas e cientistas sociais, tendo contribuído, significativamente, para os progressos do campo. 6 - Ge ofísica, Aeronomia e Física do Espaço - Fronteira entre a física e as ciências da terra e do espaço.

Como visão geral das a tividades in terdisciplinares, no País, podemos dizer que as áreas que fazem fronteira com assuntos tecnológicos têm surgido, principalmente, como consequiência do reconhecimento, pelos próprios físicos, do interesse de certos aspect os de sua pesquisa. $O$ crescimento relativo dessas áreas mostra o aumento de interesse dos pesquisadores em darem uma contribuição prática e material imediata à sociedade em que vivem, além das suas contribuiçồes culturais e educacionais.

0 desenvolvimento e for talecimento de projetos interdisciplinares deve ser meta prioritária, desde que esta è uma das maneiras mais diretas, pelas quais a física interage com a sociedade. Programas deste tipo devem envolver Talunos, desde a fase dos estudos de graduação, através de bolsas de iniciação científica, devendo-se criar e ministrar disciplinas que levem a estudos in terdisciplinares. Da breve descriçáo apresentada, fica claro que o sucesso de programas interdisciplinares depende do desenvolvimento prévio ou simultâneo dos principais ramos de pesquisa em física básica". (CNPq, Avaliação \& Perspectivas, 1978; 60-64, 76 - subárea de Física)

A longa referencia expressa uma perspectiva inter dis. ciplinar vinda do interior de uma ciência do campo das cha. madas exatas. Aí está incluída uma ilação de que, a aborda. gem em tela, faz uma aproximação entre a disciplina, a tecnologia e áreas de interesse da sociedade. A listagem dos diferentes campos interdisciplinares, tangentes à física, ilustra a possivel ocorrência de experiências e por isso inclui, também, algumas cautelas como: a qualidade das contribuiçōes específicas de cada disciplina, a hipótese da interdisciplinaridade começar na graduação e a oportunida. de de bolsas de iniciação. No conjunto dos demais textos esse é o que desce a maiores de talhes práticos.

2 - Na área de Ecologia

"A abertura de novos cursos de pós-graduação deve levar em conta situaçōes ecológicas regionais e a possibilidade de implantação de programas de pesquisa, de largo espectro, nos ecossistemas locais com ênfase em aspectos interdiciplinares.

A implantação de grupos de pesquisa ecológica no Nordeste, em atividades interdisciplinares e que possam contribuir para um maior desenvolvimento do campo da ecologia, nessa região.

Cadernos de Saúde Pública, R.J., 3 (3): 266 -271, jul/set, 1987 
A partir desse programa e do desenvolvimento científico que um esforço interdisciplinar, desse nivel, porporciona, poder-se-á contar com equipes treinadas com uma visão sistêmica do problema e com capacidade de interpretação muito mais elevados, do ponto de vista científico e de grande interesse em aplicação". Nesta área, que deriva de uma disciplina de estrutura mais recente, a ênfase inter. disciplinar é mais estrutural que nos demais casos. (CNPq, Avaliação e Perspectivas, 1978: 18, 20, 21, 22 - Subárea de Ecologia )

3 - Nas áreas de Alimentação e Zoologia as referências são indiretas, isto é, não referem, explicitamente, a interdisciplinaridade, mas referem a conjugação com áreas afins.

03 - Sinopse de 1982.

Inter disciplinaridade em documentos de "Avaliação \& Perspectivas, do CNPq, 1982 ; área de Ciência da Saúde.

Um estudo inicial do volume, disponível na biblioteca da Escola Nacional de Saúde Pública, mostra o resultado organizado na tabela a seguir (Tabela II) como um primeiro nível de dados.

Referências à prática ou d̀ expectativa de multidisciplinaridade ou in terdisciplinaridade, em uma A valiaçāo da área de Ciências e Saúde

\begin{tabular}{|c|c|c|c|}
\hline Número de Ordem & Subárea & Subtítulo & $\begin{array}{l}\text { Referência direta, indireta, } \\
\text { sem Referência }\end{array}$ \\
\hline $\begin{array}{l}1(" 36 ") \\
2(“ 37 ")\end{array}$ & $\begin{array}{l}\text { Cirurgia e Especialidade Cirúrgicas } \\
\text { Educação Física, Fisio terapia, Terapia } \\
\text { Ocupacional, Fonoaudiologia }\end{array}$ & Educação Física & $\begin{array}{l}\text { Não tem referência } \\
\text { Referência direta }\end{array}$ \\
\hline $3(" 38 ”)$ & Enfermagem & Enfermagem & Referência direta \\
\hline 4 ("39") & Farmacologia Clínica & & Não tem referência \\
\hline $5(" 40 ")$ & Materno-Infantil & Materno-Infantil & Referência direta \\
\hline $6(" 41 ")$ & $\begin{array}{l}\text { Medicina Interna e Especialidade não- } \\
\text { Cirúrgicas }\end{array}$ & & Não tem referência \\
\hline $7(“ 42 ”)$ & $\begin{array}{l}\text { Medicina Preventiva e Social e Saúde } \\
\text { Pública }\end{array}$ & $\begin{array}{l}\text { Medicina Preventiva } \\
\text { Saúde Pública }\end{array}$ & Referência direta \\
\hline $\begin{array}{l}8 \text { (“43") } \\
9 \text { ("44") }\end{array}$ & $\begin{array}{l}\text { Nutrição } \\
\text { Odontologia }\end{array}$ & Nu trição & $\begin{array}{l}\text { Referência direta } \\
\text { Não tem referência }\end{array}$ \\
\hline 10 (“45”) & Patologia & Patologia & Referência indireta \\
\hline Totais 10 & & & $\begin{array}{l}5 \text { (Referência direta) } \\
1 \text { (Referência indireta) } \\
4 \text { (Sem Referência) } \\
\end{array}$ \\
\hline
\end{tabular}

Fonte: CNPq. Avaliaçāo e Perspectiva 1982

Área de Ciência da Saúde 523 pp.

SS: eba

Legenda: 0 - Referência dureta

$\phi$ - Referência indireta

- - Sem Referência

O que esta tabela oferece, explicitamente, é um sinal de uma preocupação mais qualitativa e menos verbalista, em relação à in ter disciplinaridade. Isto quer dizer que, além de 
referir o termo dentro do âmbito da pesquisa e da graduação ou da pós-graduação, surge um esforço para tirar conseqüências, para referir uma história de experiências, para detalhar práticas e distinguir sua aplicabilidade melhor, neste lugar ou, ainda, não ocorrida em outros casos. Surge, até mesmo, um cer to senso das limitacões e cer ta nostalgia por situaçōes que ficaram para trás.

Especificamente falando, é possivel compor, como que um grande painel com o conjunto das referências recapituladas, dentro de uma tipologia preliminar.

1 - O nivel da nomencla tura. In terdisciplinar aparece associado com multidisciplinar, integração, cooperação, multiprofissional, coletivo. Associação, aqui, não é o mesmo que equivalente. Por exemplo:

"Deverão, na área da Saú de, ser a tendidos os aspectos que se referem a ações de alcance individual, ligados à assistência médica integral no âmbito da prevenção, promoção, tratamento e reabilitação, bem como ações de alcance cole tivo e nultidisciplinar" (CNPq, Avaliação \& Perspectivas, $1982: 224$ ).

2 - 0 termo interdisciplinaridade aparece ligado à proposta de programação:

"O programa propõ̀e-se a apoiar a formação de grupos interdisciplinares e regionais, e o intercâmbio entre eles, com grupos de planejamento e execução" (CNPq, Avaliação e Perspectivas, 1982: 421 : subárea de nutrição e alimentação).

3 - O termo aparece como expressão de uma lacuna sentida: "Em sua maioria, as pesquisas não são in terdiscinlinares e não são centradas em temas-problema, mas predominam as do tipo "acompanhamento" e as que reproduzem experiências alhures" (CNPq, Avaliação e Perspectivas, 1982: 323; 221; 79 - respectivamente, nas subáreas de Medicina Interna e Especializada, Saúde Materno-Infantil, e Educação Física).

4 - O termo aparece em um contex to de história recente: "O ordenamento das disciplinas deverá ser modificado. Os alunos, a o passarem por disciplinas da área básica, tais como: Ana tomia, Fisiologia, Bioquímica, Bioestatística, e tc., recebem uma carga de ensinamentos teóricos e algumas demostrações práticas em animais, cuja importância e aplicações, no exercício da medicina, desconhecem. Dois a três anos após, passam a valorizar o que lhes foi ensinado e não foi aprendido. Tentando corrigir esse tipo de situação, em 1952, a Escola de Medicina da "Western Reserve", nos Estados Unidos, propôs, pela primeira vez, o ensino, a través de programas multidisciplinares, onde se consegue uma integração interdisciplinar e multidisciplinar - Este tipo de ensino, também chamado "em blocos", tem sido utilizado por 
várias outras escolas de medicina, inclusive em nosso país, onde pioneira foi a Faculdade de Ciências da Saúde, da Universidade de Brasília (UNB), que o utilizou nos seus primórdios, com grande satisfação docente e discente $-O$ ensino "em blocos" permite uma excelente in tegração entre disciplinas básicas e clínicas. $\mathrm{O}$ aprendizado das ciências básicas se faz com o concurso de docentes das áreas clínicas. Por sua vez, a integração interdisciplinar entre áreas clínicas, também é conseguida, pois, o ensino é conseguido de forma conjunta. O sistema de blocos evita a atomização do conhecimento e talvez seja a única maneira de se integrar os docentes e a docência" (CNPq, Avaliação e Perspectivas, 1982: 235-236, su bárea de Saúde Ma terno-infantil).

5 - O termo é tomado para expressar uma articulação com a estrutura de uma disciplina:

"A Fonoaudiologia insere-se nas Cièncias da Saúde, pois, abrange, fundamentalmente, os três níveis de atenção da mesma: preventivo, curativo e reabilitacional, mas tem, antes de tudo, um caráter multidisciplinar, pelas significativas interfaces com as Ciências Sociais Aplicadas: Lingüística, Psicologia, Educação", (CNPq, Avaliação e Perspectivas, 1982:117, Subárea de Fonoaudiologia).

6 - O termo é usado com relação à possibilidade de publicaçâo:

"O pesquisador deve publicar seu trabalho, quando achar que está amadurecido e consistente, e que outros terão oportunidade de julgá-lo, sem objeções que não sejam as de discussão de conteúdo do trabalho. Isso incorpora outras influências quando a pesquisa passa de individual e isolada para uma pesquisa institucional e de grupo multidisciplinar", (CNPq. Avaliação \& Perspectivas, 1982: 152, subárea de Enfermagem).

7 - Bem mais complexoé o uso do termo no contexto da experiência que obteve patrocínio institucional, seja do Brasil seja do exterior:

"Foram feitas tentativas para promover a cooperação interdisciplinar em problemas que afetam a saúde, cujas raízes estão na estrutura social e econômica. De 1974 a 1977, CNPq, Capes, Fadesp e Fundação Ford mantiveram o Programa Multidisciplinar de Nutriçâo que aprovou auxilios para pesquisa e treinamento na área de nutrição e alimenta. ção, envolvendo cientistas de saúde, tecnologia de alimentos, sociólogos, economistas, psicólogos e administradores. Dois estudos, por grupos in terdisciplinares, produziram uma análise epidemiológica e social da desnutrição na cidade de S. Paulo e no agreste pernambucano, e está em início, um proje to de cooperação in terdisciplinar sobre variáveis envol. vidas na mortalidade infantil, em Recife. A avaliação de al. guns programas do INAN atraiu, para a área de nutrição, 
cientistas sociais da Universidade Federal de Viçosa, do Instituto de Pesquisas Econômicas da USP e do Instituto Joaquim Nabuco de Estudos Sociais, de Recife. A Associação de grupos e a interdisciplinaridade são estra tégias flexíveis, promovidas em função do interesse da sociedade e desativadas, logo que sua função tenha sido cumprida (grifo deste autor), (CNPq, Avaliação e perspectivas, 1982: 36-37, subárea de Nutrição).

8 - Finalmente, o emprego do termo e as práticas relacionadas à subárea de Saúde Pública parecem esboçar, como fundamento, uma teoria da multicausalidade e suas conseqüências:

- "Os estudos em andamento, nesta subárea, mostram a preferência pela análise das condições de saúde da população e seus indicadores, determinantes biológicos sociais e ambientais e avaliação das políticas. Foi, recentemente, criado um centro de Estudos e Pesquisas em Antropologia Médica que evoluiu de uma série de projetos sobre práticas alimentares e de saúde, em várias regiōes do país. Entâo sendo implantados alguns programas de integração docente-assistencial, de natureza interdisciplinar. Existe um in teresse crescente em saúde ocupacional, face aos riscos criados pela tecnologia da agroindústria moderna e pelos setores de ponta da produção industrial. Atenção crescente vem sendo dada a moléstias crônicas degenerativas, seus determinantes sociais e à influência de modificações do ambiente, na determinação da doença. A organização da assistência médica em áreas rurais e urbanas, a tecnologia em atençấo primária e a pesquisa operacional em saúde pública vêm despertando uma atenção crescente. - Essa a tividade se desenvolve, em grande parte, com iniciativa pessoal sem participação e sem apoio das instituições de ensino. A consolidação de grupos com linhas bem definidas de trabalho, sua integração com as políticas de saúde pública $e$ sua contribuição para a avaliação destas políticas estão, ainda, em fase inicial e dependem do suporte continuado que lhes for dado pelos organismos de apoio ao desenvolvimento científico. Essa consolidação da subárea em grupos de análise e planejamento em saúde não poderá prescindir de uma intima cooperação com as ciências sociais. Tanto as atividades de pesquisa conı de ensino deverāo desenvolver-se em un contex to de prestação de serviços".

(CNPq, Avaliação e Perspectivas - 1982:38-39, Subáreา de Saúde Pública, Medicina Comunitária e Social).

04 - Notas para discussão.

a) A análise das referências de 1978 e de 1982 reúne materiais, cujo ponto de contacto é a alusão à interdiscipli- 
naridade. Como parte de uma análise, ainda em processa. mento, o conjunto de 1978 examinou várias áreas e o de 1982 se ateve, apenas, a uma delas. A estrita disponibilidade do material limitou o exame exaustivo, mas esta limitação, de algum modo, constrói como que uma mostra não-intencional. No conjunto, ressalta a constância da interdisciplinaridade, como preocupação, na área das ciências exatas, das ciências sociais aplicadas e de disciplinas, cuja estrutura faz apelo a interseções como a Ecologia ou a Saúde Coletiva, ainda, sob o nome de Saúde Pública.

Nos textos selecionados, aparece como que um lento acúmulo de esforços, em direção à construção social das caracter ísticas da in terdisciplinaridade. Tipicamente in terface, as várias indicaçōes da experiência desvendam as práticas que são recorrentes, sob a "máscara social" da interdisciplinaridade. Quer dizer, aí surgem traços tais como: a) memória crítica de experiências que aparecem em andamento, descontinuadas ou desejadas, isto é, recomendadas; b) a percepção de limitações da in terdisciplinaridade (programas provisórios, flexíveis); c) a raiz de certo modo conjuntural, mediante as respostas dadas a necessidades da sociedade; d) o registro e o reconhecimento de apoio vindo do exterior (Fundação Ford) ou de agências nativas como o $\mathrm{CNPq}$, a FINEP, A Capes, a FAPESP; e) a afirmação de situações onde o que há de interdisciplinar tem uma constituição oriunda das combinações que levaram à disciplina como é o caso da fonoaudiologia, da ecologia, e das áreas interdisciplinares rèlacionadas com a Física.

Retrospectivamente, pode-se perguntar: como o conceito de interdisciplinaridade foi provocado a se inserir nos documentos do $\mathrm{CNPq}$ ? Conotando muito mais a iniciativa das diferentes disciplinas do que um item da política oficial, $o$ acervo de alusōes às práticas abrange, também, uma porção de ideologia, na direção das ciências aplicadas e da tecnologia. Fica patente a lacuna de uma teoria consistente do processo de construção do conhecimento interdisciplinar. É dinâmica e não mágica a relação entre interdisciplinaridade e totalidade.

b) As praticas de interdisciplinaridade resumidas, nos documentos de "Avaliação e Perspectivas, se baseiam em que pressuposto teórico? - Nesta discussão o conceito de teoria é muito mais do que uma possibilidade de generalização, a partir de um arcabouço de análise e de abstração. Pelo contrário, aqui, a teoria inclui uma necessária visão crítica do que seja uma argumentação que não pode ser neutra e que se situa em um processo do conhecimento, a um tempo sobordinado e resistente aos parâmetros coloniais do passado e pós-coloniais (via imperialismo das multi- 
nacionais ou padrões de dominação com tentáculos, já den. tro "de casa", e não, só vindos do exterior, como lembra muito bem Miriam Palmeira, 1985). Dito de outro modo, a discussão, que vale a peña enfrentar, é aquela que inclui a caracter ística de inserção histórica do conhecimento e de suas contradições; a autora, antes referida, chama a isso de "inserção sócio-histórica" do conhecimento.

O pós-colonial tem que ser levado em conta pelo fato de que o campo de forças do mesmo é uma barreira para a emancipação de quem opera como contraforça, em relação a quem detém papéis hegemônicos. 0 modo de pensar póscolonial se agarra à acumulação de poder e, portanto, se recusa a acatar outra voz, outro voto, outra opção. As críticas, feitas ao taylorismo e ao "homem unidimensional", são reforçadas pela perspectiva interdisciplinar, na medida em que ela se insurge contra o que Hilton Japiassú discutiu como "Patologia do saber" fragmentado. Por sob a direção descolonizadora possível existe, também, a história da ciência refletida na história da conexão de diferentes disciplinas que convergem não tanto por si mesmas, isolada. mente, mas por efeito de uma demanda e de uma perspectiva que vem da sociedade.

c) A interdisciplinaridade não pode ser confundida como uma espécie de pulsão hegemônica ou com a exclusiva gênese de novas disciplinas. Experiências houve que derivaram em novas disciplinas: Ecologia, Fonoaudiologia, Bioestatística, Geofísica, Biotecnologia. Mas estes casos indicam um patamar entre aqueles possíveis. A interseção temporária será outro patamar. Em todo caso, o temporário ou o aspecto mais permanente indicam etapas diferentes do processo interdisciplinar ou do esforço de desfragmentação.

Conviver coin a unidisciplinaridade é um postulado fundamental desta discussão. Até porque não haverá boa interdisciplinaridade, sem o pas o constitutivo dos pontos de vista, com uma tradição especitica.

Em algumas situações, a abordagem interdisciplinar visa, especialmente, no âmbito de programas e de serviços, tomadas de posição mais pragmáticas que, puramente acadêmicas. Entre o conhecimento puramente acadêmico $\mathrm{c}$ a tecnologia, a interdisciplinaridade avança em uma articulação que ultrapassa o senso estrito do tipo de evidência cartesiana geométrica; ela se constitui em categorias de angulação múltipla, especialmente, considerando a urgência de não separar ciências exatas e ciências humanas, sem anular a especificidade de cada uma delas.

Desse modo é que pode-se entender como a análise da interdisciplinaridade, feita pelo matemático e filósofo Sinaceur Muhammed Allal (1977), chamou a atenção para a 
possibilidade de tratar a referida abordagem, enquanto instrumental, para decisões. Então não se trata, apenas, de ter uma escolha de alternativas, mas ter um tipo de argumentação fundada na recorrência de perspectivas que se reúnem em lugar de indicações isoladas. O principio da prova recorrente e multiplicada decorre de um sistema aberto e tenta dar solução para o problema da "ars gratia artis" ou da ciência, por si mesma, diletante. Ele tenta dar resolutividade para a possibilidade de cruzamentos férteis, entre as diferentes perspectivas. E, nessa linha de argumentação, é bom recordar o documento da OMS sobre cooperação intersetorial; examinando o Centro de Desenvolvimento em Educação e Saúde (Arustra., Tanzânia) ali se refere: "Os professores do futuro devem ser bons planejadores e gestores e não somente especialistas, em determinados assuntos" (1986:22). Com isto, emerge a al ternativa de que a interdisciplinaridade contribua para semear um tipo de profissional que ligue o conhecimento - à visão alternativa e à praticidade.

d) De um ponto de vista político, ou seja, de uma efetividade da contribuição interdisciplinar é importante notar que o tipo de argumentação ou de prova resultante, não se destina, exclusivamente, a uma absorção ou a um uso intradisciplinar. Pelo contrário, a direção da demanda, pela análise interdisciplinar, pode seguir cạminhos críticos diferentes: ou se originar de um profissional unidisciplinar, porém, visando um resultado que ultrapassa o seu campo único e se orienta para respostas a problemas novos ou a respostas a problemas colocados pela sociedade; ou se originar em um primeiro passo de uma demanda, vinda da sociedade, em uma situação de apelo a uma "junta médica" (por analogia), dado o inusitado ou a gravidade, seja mo. mentânea, seja estrutural, de certo problema. Por exemplo: os chamados relatórios de "impacto ambiental", os problemas e soluções colocadas pela 8 a Conferência Nacional de Saúde, ou o tema da Aids, bem como o problema da cons. trução de naves espaciais ou de colonias espacíais. Nesses casos, o que pode haver de político está, em primeiro lugar, combinado com um princípio elementar de epistemologia: a recorrência de reforços para provas que não são mecânicas, axiomáticas e invulneráveis: e em segundo lugar: a presença de um tipo de parceiro no jogo da descoberta (aquele que vai tomar decisões com base na força maior ou menor de dados convergentes vinda de disciplinas diferentes, fazendo assertivas, basicamente, ligadas à especificidade de cada campo, mas qualificada pela colaboração in tersetorial ou inter disciplinar). Há, pois, uma situação de incerteza ou de risco, pedindo um tratamento de "paradigma" diferente daquele da unidisciplinaridade; e há a

Cadernos de Saúde Pública, R.J., 3 (3): 280-296, jul/set, 1987 
construção social do contra-risco, que serão as premissas, levando a uma decisão ou a decisões, cujo efeito ultrapassa um processo de isolamento e fragmentação. O tema do poder, imbricado no processamento interdisciplinar da descoberta, ainda está rela tivamente intocado? - É possível alertar, pelo menos, para duas situaçõos em que esse poder foi reduzido à inocuidade : no caso da hidroelétirca de Tucuruí (Pará) as análise de Robert Goodland resultaram em recomendações das quais, provávelmente, 9/10 não foram implementadas; no caso de um dos conselhos técnicos, de uma grande estatal brasileira, realizando trabalho de alta complexidade e implicando a Amazônia, um biólogo conselheiro indicava, frustradamente, que a totalidade de suas recomendações não eram acolhidas. Esses dois casos, apenas, dramatizam o lado político da interdisciplinaridade.

e) Há, também, o aspecto, em parte, levantado pelos ${ }^{-}$ relatores dos textos de avaliação e perspectivas: a interdisciplinaridade no conjunto das práticas (Quatro disciplinas de um total de vinte e seis, no caso da tabela I, e seis de um total de dez, no caso da tabela dois) é quase uma exceção, levando-se em conta que a freqüência na listagem ulterior, apenas, tomou - como um exercício - uma área, enquanto que, a outra tomou a maioria das áreas. As duas séries ainda não permitem, sozinhas, uma conclusão melhor do que aquela que considere os dados, ainda, como emergentes.

Independentemente da questão quantitativa, existe o ponto de vista qualitativo, Por exemplo: o posicionamento dos Físicos e o posicionamento dos Ecólogos não são, qualitativamente, insignificantes. Aí, não foram colocadas apenas as espectativas ou um vago impressionismo; além do mais, no caso da Física, eles já falam de práticas com uma certa história.

Resta a discutir se, no caso da interdisciplinaridade, "dois olhos veem ma is do que um". Nesse ponto, existe o problema histórico de que as disciplinas foram se constituindo por fragmentação e, em alguns casos, por rejunção: quando Galileu reagrupa disciplinas e realiza o que foi chama do de "matematização da Física", ou quando geógra. fos brasileiros assumem a posição de "historização da geografia" ou tomam o espaço como "espaço interdisciplinar". Que se passa? Galileu negou a Física? ou negou a Matemática? -Ficando a salvo, o que era característico de cada contribuição, o reagrupamento opera uma conjunção de pontos de vista que passam pelo crivo do que podemos cli.. mar de passo em direção às mesmas cautelas, que teria uma comunidade, científica, velando pela qualidade dos argumentos, mas também, velando pelos desdobramentos que o uso das disciplinas traz em seu bojo: basta lembrar o caso Oppenheimer, o caso Camlot ou, então, o recente proble- 
ma entre psicanalistas e a tortura. Nesses casos a hipótese fica, relativamente, aluída pelo desvio tangente à ética profissional, mas que, também, é uma questão de comunidade científica resguardando o fluxo possível entre disciplinas e suas conseqüencias (boas ou más) para terceiros.

f) Um ponto de importância - porque tenta desvendar a relação entre práticas e estruturas - diz respeito à questão: como a interdisciplinaridade emerge, concretamente, para fora da "torre de marfim" conceitual? Ou que indicadores de instâncias concretas vêm à cena?

Tais indicadores são interessantes, desde que colocados em um contex to de um processo crítico. $O$ conceito de crítica, adicionado a um processo, traz à mente a idéia de movimento, mas aproveitando as próprias contradições, como uma fonte de descoberta e de ultrapassamento. Assim, o que já existe não exaure aquilo que ainda não existe; dito de outro modo, o conceito não revela, inteiramente, a estrutura e a estrutura não revela, inteiramente, as práticas. Mas, por meio do vestígio das práticas é que a ideologia se exprime e se expõe à crítica, a estrutura "diz" sem indicar transformações por que ela passa no confronto com a "tradução" da mesma, ao fazer face a situaçōes no campo das práticas.

Com esses pressupostos, o sentido das práticas é retomado como refletindo o que existe e o que ainda não existe. Para fins de discussão, este item retoma o título do estudo e tenta torná-lo coerente com a expectativa de que a interdisciplinaridade existe, além do discurso. 0 quadro a seguir é uma tentativa de listar instâncias ocorrentes e instâncias, ainda, não ocorrentes mas que, por conseqüência da necessidade de construção da identidade, faz, dos traços, uma tentativa de esboço do que é possível haver de concreto, na relação entre estruturas e práticas:

\begin{tabular}{|c|c|c|}
\hline Instância concreta & já encontrada & possível ou em aberto \\
\hline $\begin{array}{l}\text { Co-autoria docen- } \\
\text { te. }\end{array}$ & $x$ & \\
\hline $\begin{array}{l}\text { Co-autoria de ori- } \\
\text { entação. }\end{array}$ & $x$ & \\
\hline $\begin{array}{l}\text { Co-autoria em } \\
\text { pesquisa }\end{array}$ & $\mathrm{x}$ & \\
\hline $\begin{array}{l}\text { Co-autoria em } \\
\text { bancas de exame. }\end{array}$ & $x$ & \\
\hline $\begin{array}{l}\text { Co-autoria em } \\
\text { bancas de sele ção. }\end{array}$ & $x$ & \\
\hline $\begin{array}{l}\text { Co-autoria em ser- } \\
\text { viços (equipes } \\
\text { multiprofissionais). }\end{array}$ & $\mathbf{x}$ & \\
\hline
\end{tabular}


Instância concreta já encontrada possível ou em aberto

\begin{tabular}{|c|c|c|}
\hline $\begin{array}{l}\text { Co-au toria empro- } \\
\text { jetos para o nível } \\
\text { de decisão. }\end{array}$ & & $\mathbf{x}$ \\
\hline $\begin{array}{l}\text { Clima conducente } \\
\text { e valorizador da } \\
\text { estratégia de sim- } \\
\text { pósios freqüentes. }\end{array}$ & & $\mathbf{x}$ \\
\hline $\begin{array}{l}\text { Organização de- } \\
\text { partamental por } \\
\text { tema multidisci- } \\
\text { plinar. }\end{array}$ & & $x$ \\
\hline $\begin{array}{l}\text { Clima conducente } \\
\text { à interdisciplinari- } \\
\text { que reúna destina- } \\
\text { tários e processa. } \\
\text { dores. }\end{array}$ & & $x$ \\
\hline $\begin{array}{l}\text { Permanentes re- } \\
\text { troalimentaçōes } \\
\text { para a relaçäo en- } \\
\text { tre a teoria - as } \\
\text { práticas - a inser- } \\
\text { ção histórico-so- } \\
\text { cial. }\end{array}$ & & $x$ \\
\hline $\begin{array}{l}\text { Práticas de inter- } \\
\text { disciplinaridade } \\
\text { em niveis anterio- } \\
\text { res à pós-gradua- } \\
\text { ção. }\end{array}$ & & $x$ \\
\hline $\begin{array}{l}\text { Práticas de inter- } \\
\text { disciplinaridade } \\
\text { como item de } \\
\text { eventos periódi. } \\
\text { cos }(100,250 \text { ani. } \\
\text { versário). }\end{array}$ & $x$ & \\
\hline
\end{tabular}

A listagem acima, apenas, abre a possibilidade de consideração de alternativas. $O$ aspecto pertinente é que uma única prática não dá conta do conjunto das possiblilidades institucionais. $O$ fato de haver mais itens na coluna dos possiveis. apenas, sugere que o assunto está em andamento e que as práticas de unidisciplinaridade ainda são as dominantes ao ilhar disciplinas e instâncias de passagem, do dis. curso à concretização.

g) Finalmente. entre as conclusões da 8 ạ Conferência Nacional. de Saúde, existe uma parte que diz respeito à 
composição de "equipes multiprofissionais" como um dos princípios relacionados com uma política de recursos humanos, nos seguintes termos: ". . . composição de equipes multiprofissionais, considerando as necessidades da demanda de atendimento de cada região e em consonância com os padrões mínimos estabelecidos pela cobertura assistencial" (Tema 2).

Tal como está expresso o item acima suporta, pelo menos, duas leituras. Uma, influenciada pelas preocupações com a demanda e com a extensão de cobertura e com padrões mínimos. Outra, se a letra desse tópico for tomada em conexão com o espírito do documento, onde a perspectiva de interdisciplinaridade é afirmada pelo próprio concẹito de saúde (Tema I), que se coloca sob o ângulo da multicausalidade. Mas, adicionalmente, o sentido das equipes multiprofissionais ganha significação no contex to de ou tras grandes linhas do documento: a integração, o destaque para participação em processos decisórios, a descentralização. A descentralização nāo pode ser entendiđa como um meio de fazer concessões à fragmentaçāo, mas como um meio de resistir ao absolutismo e à cegueira do poder acumulado, que "julga a todos e por ninguém é julgado". Quanđo o documento fala que problemas de saúde ocorrem, como efeito de "dadas formas de organização da produção" é possível desdobrar a sentença lembrando que existem, outrossim, "formas de organização do conhecimento" que admitem a fertilidade heurística dos processos, em oposição à tomada de verdades particulares e de classe como se fossem verdades universais e da sociedade. Mas, é bom lembrar que para os fins da pesquisa, do ensino ou dos serviços, as formas de organização para processar e gerenciar o conhecimento de nível interdisciplinar ainda são, de algum modo, exceções e tentativas quase sem o peso de uma tradição.

1111111111111111111111111111111111111111111111111111111111

In two parts, this paper deals with the theme in interdisicplinarity and its place both in programs of higher education and services as well as in the frame of health related disciplines. The first part sums up an agenda for-research of the topic. The second part advances a step further and points to the use of an interdisciplinary approach within health programs of teaching and researching: basic data were taken from secondary sources "Avaliação e Perspectivas"(CNPq - 1979 and 1982). As an an thropologist, the auth or looks for a social anthropoloyg-land". 
BURTON, MICHAEL L., G. MARK SCHOEPFLE, MARK L. MILLER. 1986 - Natural Resources Anthropology, in Human Organization Vol. 45, N. 3:261-269.

COIMBRA, CARLOS. 1982 - Interdisciplinaridade. Seminários do NAEA (Núcleo de Altos Estudos Amazônicos). Texto principal de Coimbra e contribuiçōes de Benedito Nunes, Nazareno Noronha, Samuel Sá. NAEA, UFPa., Belém, Pará.

DINSMORE, PAULO CAMPBELL e PAULO JACOBSEN. 1985 Prosolve. Processo decisório - da criatividade à sistematizaf̧ão. CDP Editora. Rio de Janeiro.

GOZZER, GIOVANNI. 1982 - Interdisciplinarity: a concept still unclear. in Prospects - Vol. XII, No. 3:281-293.

GUSDORF, GEORGES. 1982 - Prefácio de Interdisciplinaridade e Patologia do Saber'. Imago editora. Rio de Janeiro. 1977 Past, present and future in interdisciplinary research, in International Social Science Journal, Vol. XXIX, No. 4:580600.

JAPIASSÚ, HILTON. 1982 - Interdisciplinaridade e Patologia do Saber. Imago editora. Rio de Janeiro, R.J.

LIMOEIRO, MIRIAM. 1985 - O conhecimento e a realidade, in Artes visuais na Amazônia, pp. 161-183. Funarte (R.J.) SEMEC (Belém, Pará).

MENDES, ARMANDO. 1984 - Interdisciplinaridade e Associaçōes Científicas Anais da ANPEC (Associação Nacional de Pesquisa e Pós-graduação em Economia). Brasilia, D.F. 1986 - O Núcleo de Altos Estudos Amazônicos. A propósito da lotação de seus docentes e pesquisadores. Mimeo. NAEA, Belém, Pará.

NUNES, EVERARDO DUARTE (organizador). 1986 - As ciências Sociais da Saúde - Organização Pan-Americana da Saúde. Washington D.C.

PIAGET, JEAN. 1973 - Problemas gerais da investigaçäo interdisci. plinar e mecanismos comuns. Livraria Bertrand. Portugal.

POSEY, DARRELL ADDISON. 1983 - Indigenous knowledge : an ideological bridge to the future. Ciencio e Culturo 35 (7): 877.894 .

REYNAUD, ALAIN et al. 1986 - O espaço interdisciplinar. Livraria Nobel. S. Paulo, S.P.

SÅ, SAMUEL. 1971 - Agentes interculturais em Arca dos Engenhos. Boletim do Museu Porcense Emilio Goeldi. Série avulsa (Sesquicentenário da In depen dência) INPA-CNPq - Belém. Pará. 1982 - Por uma Etnografia da interdisciplinaridade. Se. minários de Pesquisa do NAEA (conjunto de debatedores da pesquisa do Prof. Carlos Coimbra). UFPa. Belém, Pará. 1986 - Antropologia, educação e interdisciplinaridade. Apresentado na sessão de educação da reunião anual da Associação Brasileira de Antropologia. Curitiba, Paraná. Março, 1986.

SILVA, HELOISA MARIA CARDOSO da. 1986 - Problemas e temas interdisciplinares. In Ciêncios Humanas - Ano IX, N. 28, Agosto.

SINACEUR, MOHAMMED ALLAL. 1977 - What is interdisciplinarity? In International Social Science Journal - Vol. XXIX, No. 4, 1977:571-579.

SOUZA, EDSON MACHADO DE. 1980 - Crises e desafios no ensino superior do Brasil. Edições UFC - Fortaleza. (pp. 171, 193, 197).

Cadernos de Saúde Pública, R.J., 3 (3) : 280-296, jul/set, 1987 
PUBLICAÇÕES DE INSTITUIÇÕES OFICIAIS: ENSP (Escola Nacional de Saúde Pública). Seminário de avaliação e perspectivas - Dezembro de 1986 - $\mathrm{CNPq}$ - Avaliação e Perspectivas1978, Avaliação e Perspectivas-1982. OECD/CERI - L'interdisciplinarité: problèmes d'enseignement et de recherche dans les universités. Paris-1972. OMS - Saúde do Mundo: A cooperação intersetorial. Março de 1986. MINISTÉRIO DA SAÚDE - Brasil - VIII Conferência Nacional de Saúde. 1986. Conclusőes.

MEIOS DE COMUNICAÇĀO DE MASSA. JORNAL DO BRASIL Rio de Janeiro. 31.12.86 - Médico sugere tratar Aids no contexto dos parasitas. Caderno 1, pg. 5.30.01.87 - Fundação. .. (Fundação Interdisciplinar de Aids. Caderno 1, pg. 7). TV - PROGRAMA GLOBO CIENCIA. 21.01.87 - Apresentação sobre Centros Interdisciplinares de Ciência. Rio de Janeiro. (15 minutos). 